Natural Hazards and Earth System Sciences, 5, 777-782, 2005

SRef-ID: 1684-9981/nhess/2005-5-777

European Geosciences Union

(c) 2005 Author(s). This work is licensed

under a Creative Commons License.

\title{
Acoustic emission and released seismic energy
}

\author{
G. P. Gregori ${ }^{1}$, G. Paparo ${ }^{1}$, M. Poscolieri ${ }^{1}$, and A. Zanini ${ }^{2}$ \\ ${ }^{1}$ Istituto di Acustica O. M. Corbino, via Fosso del Cavaliere 100, 00133 Roma, Italy \\ ${ }^{2}$ Univ. degli Studi di Roma - Tor Vergata, Dipartimento di Ingegneria Meccanica, via del Politecnico 1, 00133 Roma, Italy
}

Received: 7 July 2005 - Revised: 21 September 2005 - Accepted: 21 September 2005 - Published: 13 October 2005

Part of Special Issue "Seismic hazard evaluation, precursory phenomena and seismo electromagnetics"

\begin{abstract}
Intense crises of crustal stress appear to cross large regions, and to precede by several months the eventual occurrence of some strong earthquake within them. The phenomenon is not linear, and the stress control reflects some wide scale-size rather than local effects. The stress propagation through the crust can be effectively monitored by means of acoustic emission (AE) techniques (ultrasounds). The correlation is here investigated between crustal stress crises and the total release of seismic energy within some space domain around the AE recording site. Some clear inferences can be envisaged, although a significant diagnosis of the state of the crust within a given region ought to request arrays of simultaneously operated AE recorders. Some case histories are described dealing with the Italian peninsula and with the Cephallonia Island.
\end{abstract}

\section{Introduction}

Acoustic emission (AE) provides twofold information. On the one hand, the $\mathrm{AE}$ intensity, averaged over some suitable time interval, is indicative of the amount of stress that affects some lithospheric and/or crustal slab of some (ultimately unknown) scale size. In principle, such scale size depends on the tectonic setting and it can be different in different areas. A first concern deals therefore with the assessment of such typical scale size for a given area.

Owing to an insisted and often widespread basic misunderstanding, it appears worthwhile to repeat here and to stress some physical and logical key points, which were already extensively discussed by the authors and co-workers in a few previous papers, mentioned here below. First, we use ultrasounds in a frequency range where the anthropic disturbance is completely negligible, thus allowing for robust results and for a good signal/noise ratio. In particular, it makes nonsense seeking a week-end effect. Second, ultra-

Correspondence to: G. P. Gregori

(giovanni.gregori@idac.rm.cnr.it) sounds damp off very rapidly within loose terrain. Hence, AE measurements can be carried out only on rocky outcrops, which are the surface manifestation of some huge probe of unknown extension underground. The measuring device is therefore composed of one such huge natural probe, added to our AE detecting and recording instrument. Third, consider the eventually observed large-scale spatial correlation over some large area (either regional or, maybe, even almost continental) of the measured $\mathrm{AE}$ records. For sure, no AE signal can propagate through any such large distance. However, we do observe some apparently definitely significant such correlations, suitably time-delayed, even on large distances. Such fact can be most briefly explained by referring, maybe, to a simple and expressive model. Consider a table with several glasses variously replenished with water. Shake the table. The water within every glass shall start oscillating. If a glass is completely replenished with water, an "extreme" irreversible "catastrophe" shall occur, i.e. the water shall get off the glass and drop on the table. If we monitor the water oscillating within any one glass, we shall realise that the table is trembling, being likely that somewhere it was shaken. The eventual correlation must be correctly expected with the water "catastrophe" that we do eventually observe simultaneously affecting some other glass, which is located even very far away from our monitored glass. Every aforementioned huge natural rocky probe is just like one such glass, and the "catastrophe" is the occurrence of an earthquake (or of any other pertinent "catastrophe" in the case of natural phenomena other than dealing with seismic events). The observational assessment of the spatial extension of such large scale apparent correlation provides us with the physical information about the natural scale size of the slab of crust of lithosphere that has to be likened to the aforementioned table. We stress that such viewpoint is substantially different from any previous feeling about the strictly local speculated character of the correlation between every possible local precursor and the local occurrence of an earthquake. No real physical argument can support such feeling. We must rather deal with large scale phenomena, much like it makes 
Table 1. Parameters of a few earthquakes.

\begin{tabular}{|c|c|c|c|c|c|c|}
\hline Name & date & starting time (GMT) & latitude of epicentre $(N)$ & longitude of epicentre $(E)$ & $M$ & depth $(\mathrm{km})$ \\
\hline \multicolumn{7}{|c|}{1997 Colfiorito (1997; only shocks with $\boldsymbol{M} \geq \mathbf{5 . 0}$ ) } \\
\hline \multirow[t]{6}{*}{1997 Colfiorito } & 26 September & 00:33 12.89 & $43^{\circ} 01.38$ & $12^{\circ} 52.42$ & 5.6 & 7.0 \\
\hline & 26 September & 09:40 26.73 & $43^{\circ} 01.78$ & $12^{\circ} 50.09$ & 5.9 & 8.0 \\
\hline & 03 October & 08:55 22.02 & $43^{\circ} 01.95$ & $12^{\circ} 49.90$ & 5.0 & 5.7 \\
\hline & 06 October & $23: 2453.23$ & $43^{\circ} 00.76$ & $12^{\circ} 49.79$ & 5.4 & 7.4 \\
\hline & 12 October & 11:08 36.87 & $42^{\circ} 54.13$ & $12^{\circ} 56.10$ & 5.1 & 2.6 \\
\hline & 14 October & $15: 2310.61$ & $42^{\circ} 54.11$ & $12^{\circ} 54.75$ & 5.5 & 5.5 \\
\hline \multicolumn{7}{|c|}{ Molise (2002) } \\
\hline Molise & 31 October & $11: 32$ & $41^{\circ} .76$ & $14^{\circ} .94$ & 5.4 & \\
\hline
\end{tabular}

nonsense speculating about the local causes of the rupture of an embankment along a river, rather than considering the hydrological regime of the river within its entire catchment's basin.

The second kind of information provided by AE refers to the fatigue of materials, which is characterised by the typical temporal sequence of the AE signals, which are released by the system while they are passively recorded. Such fatigue can be quantitatively investigated by a fractal analysis of the AE time series (Paparo and Gregori, 2003; Gregori and Paparo, 2004). Such information appears very likely to give relevant information for monitoring the temporal evolution of the system, during some time lag preceding its final "catastrophe". Such diagnostic information applies, however, only to some comparatively small spatial scale size (e.g. in the order of a few tens kilometres from the epicentral area), although such distance is very likely dependent of the tectonic setting and of the typical physical scale size of the structures being involved. Such aspect is not of direct concern for the present investigation (refer to Paparo et al., 2005).

The AE records here investigated were measured typically within two frequency bands, at $200 \mathrm{kHz}$ or $160 \mathrm{kHz}$ (here called high frequency, or HF AE), and at $25 \mathrm{kHz}$ (low frequency, or LF AE). Refer to Paparo et al. (2005) and Poscolieri et al. (2005) for details. Every recorded signal is the average over $30 \mathrm{~s}$ of such measurements. The signal is filtered by a specific procedure for rejecting outliers, which reflect phenomena not of concern for the present study. The resulting time series is smoothed by applying a weighted running average, over a $24 \mathrm{~h}$ time span, by using a triangular filter (with a maximum weight 1 at the centre, decreasing linearly to 0 ). In this way, the final result ought to exclude, and get rid for, the thermoelastic effects associated with the diurnal temperature cycle ${ }^{1}$ (see Paparo et al., 2002), and for some large

\footnotetext{
${ }^{1}$ The diurnal effect was clearly observed within measurements carried out on the Gran Sasso mountain, the highest Apennine range, which is an area that during the period spanned by the $\mathrm{AE}$ records was tectonically quiet. The maximum AE release was observed (as expected) during night-time, when the rocky surface of the mountain cools up, and the outer layers contract over a still ther-
}

fraction (though not all of them) of the diurnal tidal effects. Such filtered datum ought therefore to be representative of the amount of stress that is crossing some large crustal area around the AE recording site.

According to some preliminary evidence, an AE crisis, i.e. a large and almost abrupt increase of the AE signal, was observed in Italy, on two occasions, some $\sim 7-8$ months in advance for $\mathrm{HF} \mathrm{AE}$, and some $\sim 2$ months in advance for $\mathrm{LF}$ AE, when considering AE records collected at say $\sim 400 \mathrm{~km}$ from the epicentral area (see Paparo et al., 2005). Such inference appears consistent with the expectation that HF AE appear very likely to be associated with the yield of small flaws within the crust, which later coalesce into flaws of increasingly larger size, which release AE of progressively lower frequency. Some analogous evidence was investigated for the Kefallinìa (Cephallonia) Island (Western Greece) (Poscolieri et al., 2005), although the different tectonic setting, compared to the Italian peninsula, apparently plays a crucial role in determining some substantially different behaviour.

For completeness sake, let us recall that our analysis and approach deals with the time series of events, leading to the observation of an apparent precursor with some reasonable temporal resolution, although with a great uncertainty in locating the epicentral area. In contrast, a fractal analysis in the space domain (rather then in the time domain), applied to the spatial pattern of the main faults crossing a given area, appears correlated with the maximum magnitude of the shock that eventually affects every given and pre-chosen area. That is, it provides with a precursor reasonably well defined in space, although with a time uncertainty eventually even as long as a few centuries. Refer to Cello $(1997,2000)$ and Cello et al. (2000, 2002).

The time delayed correlation is here quantitatively investigated between such $24 \mathrm{~h}$ smoothed HF AE and LF AE signal, and the total (5 days time-smoothed) seismic energy that is released within some area of some reasonable size around

mally expanded inner body, unlike what happens during the diurnal warming, when the outer layers expand over a cooler and thermally less expanded internal part. For details refer to Paparo et al. (2002). 


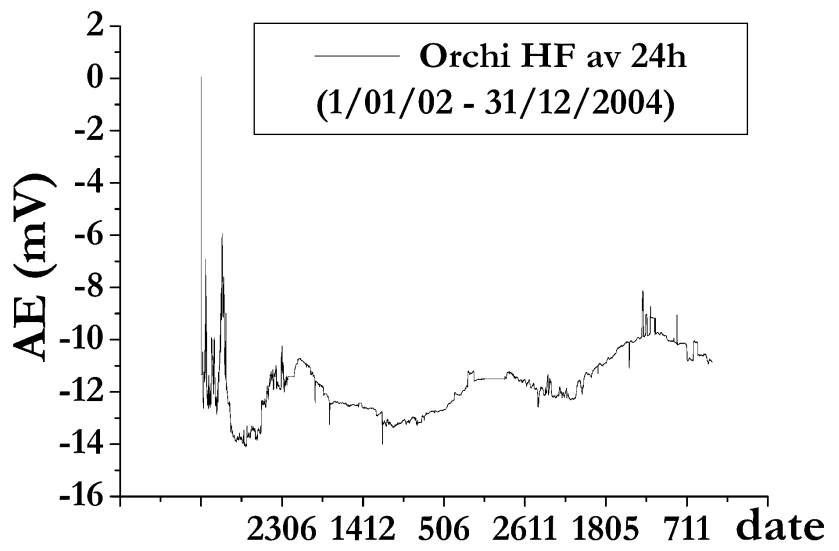

Fig. 1. Raponi site (Orchi, Foligno, central Italy). HF AE, weighted running average over $24 \mathrm{~h}$. The sharp feature on the left hand side is interpreted as a precursor of the Molise earthquake, occurred $\sim 7-8$ months later, at about $400 \mathrm{~km}$ distance from the AE recording site. Seismic phenomena do not appear to be local features. Rather they imply crustal stress crises that involve areas equal to, or maybe even larger than, the entire Italian peninsula. An annual modulation is also recognisable, which is investigated elsewhere (in preparation).

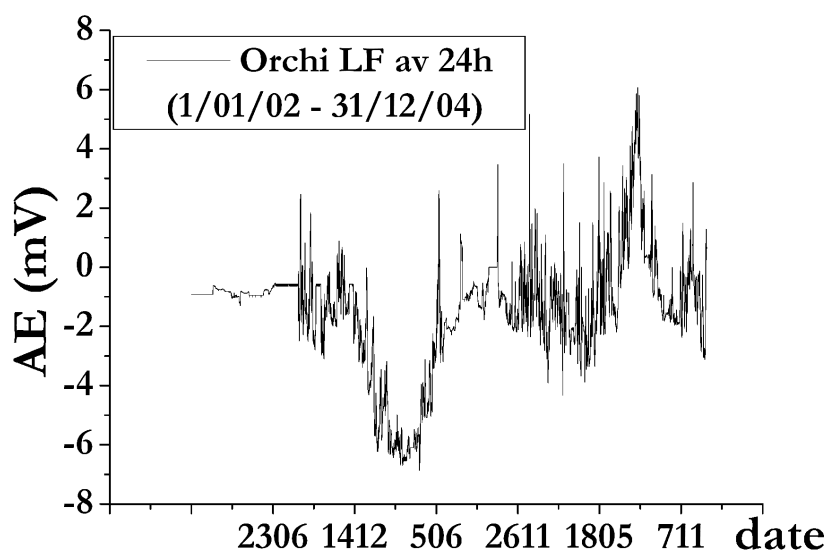

Fig. 2. The same as Fig. 1, but referring to LF AE. The abrupt change of trend, in terms of the introduction of some abrupt noise, preceded by almost exactly 2 months the Molise earthquake. The annual variation, if it exists, appears very confused and perturbed by some large noise (to be investigated elsewhere, in preparation).

the $\mathrm{AE}$ recording site. The comparison is carried out by considering the available case histories referring to the Italian peninsula and to the Cephallonia Island.

\section{The AE records}

Figures 1 and 2 refer to the Raponi site, at Orchi, Foligno (Umbria, central Italy; see Fig. 3), which is the site that has been the epicentre of the 1997 Colfiorito earthquake (see Table 1 for details ${ }^{2}$ ), also known for the great damages caused

\footnotetext{
${ }^{2}$ Source the web site of INGV (Istituto Nazionale di Geofisica e Vulcanologia, Roma).
}

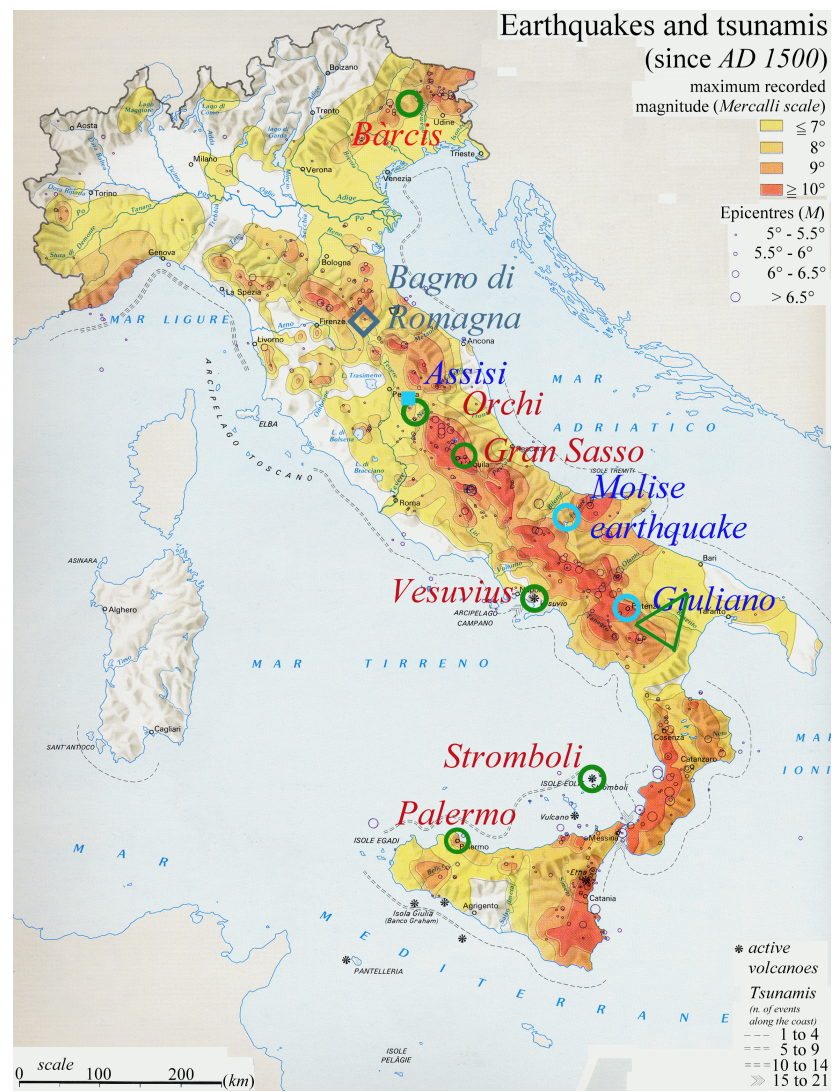

Fig. 3. Geographic map showing several sites mentioned in the present paper.

to Assisi. The AE recording was started after the occurrence of such great catastrophe. Figure 1 shows an annual modulation (to be investigated in a different study; in progress), with some anomalous large oscillation occurring some $\sim 7-8$ months before the occurrence of the Molise earthquake (see Table 1), which had an epicentre at some $\sim 400 \mathrm{~km}$ from the Raponi site. Analogously, Fig. 2 shows some incredibly sharp change of behaviour occurring almost exactly $\sim 2$ months before the shock. The essentially identical time advance was observed within records collected close to Potenza (see Fig. 3) that preceded the 1997 Colfiorito earthquake (see Table 1). Such two case histories resulted essentially geographically symmetric with respect to each other (Paparo et al., 2005).

The general pattern of Fig. 2 denotes some almost permanent state of stress of the crust with a comparatively larger peak observed on 7 August 2004. Such feature appears correlated with a comparatively large peak in Fig. 1, occurring on 3-5 August. However, one case history alone, and records collected at one site alone, cannot be significant. Such AE records indicate, however, that early in August some stress perturbation crossed such area.

Figures 4 and 5 deal with the Cephallonia results (all observations were collected by the authors and co-workers). The trend appears completely different, being the very likely consequence of the substantially different tectonic setting of 


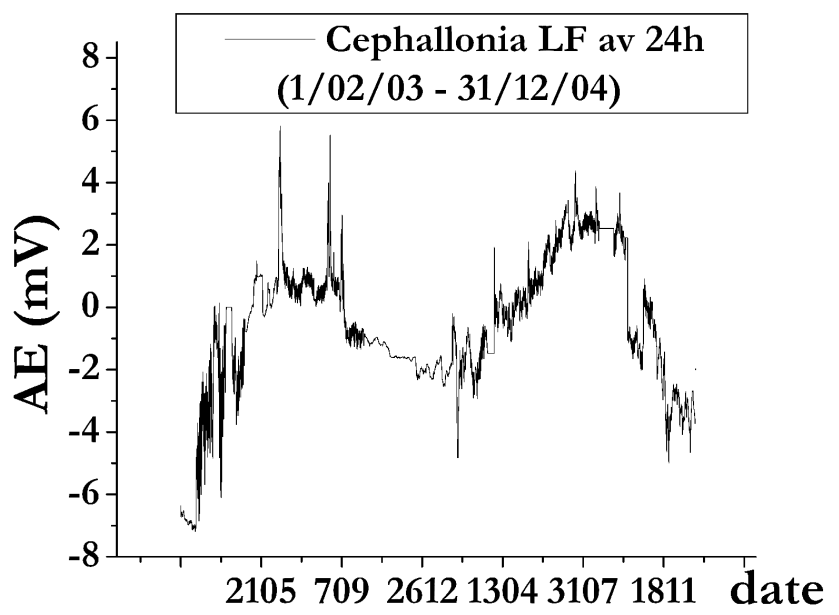

Fig. 4. Cephallonia Island. HF AE, figure analogous to Fig. 1. The annual variation appears very clear.

the two areas (Poscolieri et al., 2005). Figure 4 shows an annual variation, similarly to Fig. 1, which is to be discussed elsewhere (in preparation). Figure 5 shows a remarkable change of trend. During June 2003 through April 2004 the trend appears almost constant with sporadic minor spikes. After May 2004, some huge stress crisis is on, with a very pronounced peak on 19 June. The superposed noise seems to increase with the progress of the crisis. After October 2004 the trend appears anew almost constant, although displaying some substantially stronger noise in the background. A geophysical interpretation is premature. However, consider that every measurement is the integral of the rms AE signal, by which a sequence of increasing $\mathrm{AE}$ records implies a sum of a large number of AE bursts. This corresponds to a huge chain reaction of yielding chemical bonds, following the intensification of the externally applied stress. The entire phenomenon recalls a wavelike trend, elapsing $\sim 5$ months, maybe reminding almost about a stress soliton.

\section{The released seismic energy}

Only shocks were considered occurring within two areas, respectively, around the Raponi site, and around Cephallonia, defined by the intervals $\left(41.5^{\circ} \div 44.5^{\circ}\right.$ lat., $11^{\circ} \div 14^{\circ} \mathrm{E}$ long.) for the Raponi site, and by $\left(37.42^{\circ} \div 39.00^{\circ}\right.$ lat., $20.12^{\circ} \div 21.12^{\circ} \mathrm{E}$ long.) for Cephallonia. The energy of every shock was computed by the conventional formula used in seismology

$$
\log E_{q}=9.9+1.92 M-0.024 M^{2} \text { ergs . }
$$

The resulting point-like data series was smoothed, and thus transformed into a continuous function, by using a moving running average, and by applying a triangular filter (analogously to the aforementioned $24 \mathrm{~h}$ average) of total width 5 days. Figures 6 and 7 show the results for the Raponi site, and for Cephallonia, respectively.

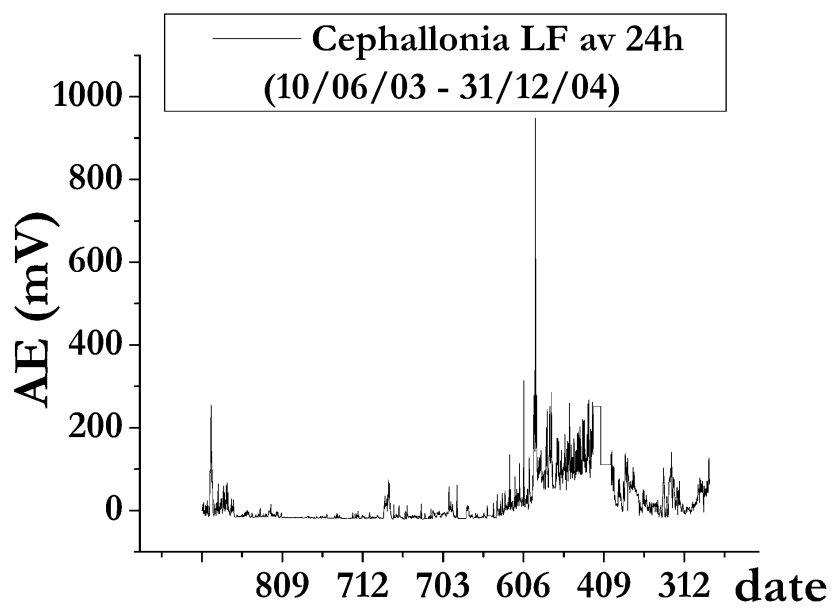

Fig. 5. Cephallonia Island. LF AE, figure analogous to Fig. 2. Compared to the case history of Fig. 2, the observed trend appears completely different. In general, a conspicuous crisis of crustal stress crosses the area, with large perturbations, associated with the great typical seismic activity of the entire area. The tectonic setting is completely different from the Italian peninsula. No reliable interrelation can be guessed, due to the limited time series of available records, and due to the lack of any adequate array of simultaneously operated AE recording sites. See text.

An additional distinction deals with the use, or not, of a spatial filter. The rationale is in searching for the possible role of local effects for the control of the observed AE. In such a respect, the estimated integral of the seismic energy release within one given pre-chosen area was computed in two ways. One way made no reference to any weight. The other way was by using a weight for every seismic shock, proportional to the inverse of the distance of the epicentre from the $\mathrm{AE}$ recording site. It resulted that the final inference appears basically independent of the use or not of such weight. This fact leads to the conclusion that the phenomenon has no local control. Rather, some physical process must be considered that should involve some significantly large area, even larger than the aforementioned domains.

\section{Time delayed correlation analysis}

The correlation coefficient $\rho(\Delta t)$ was investigated between the aforementioned smoothed AE signal and the seismic energy release, after applying a relative time delay $\Delta t$.

Concerning the Raponi site at Orchi, the HF AE give clear evidence. The aforementioned inference from Fig. 1 is quantitatively expressed by Fig. 8 , which refers to the years 2002-2003. The approximately $\Delta t \sim 7$ months time delay corresponds to a $\rho \sim 0.6$. This supports the fact that the anomalous HF AE behaviour appears to be a precursor, rather than an aftershock. However, when the years 20032004 are considered (Fig. 9), a $\rho \sim 0.6$ was found corresponding to a $\Delta t \sim 4$ months. This means that the same area shows an advance time lag of the HF AE crisis that displays some 

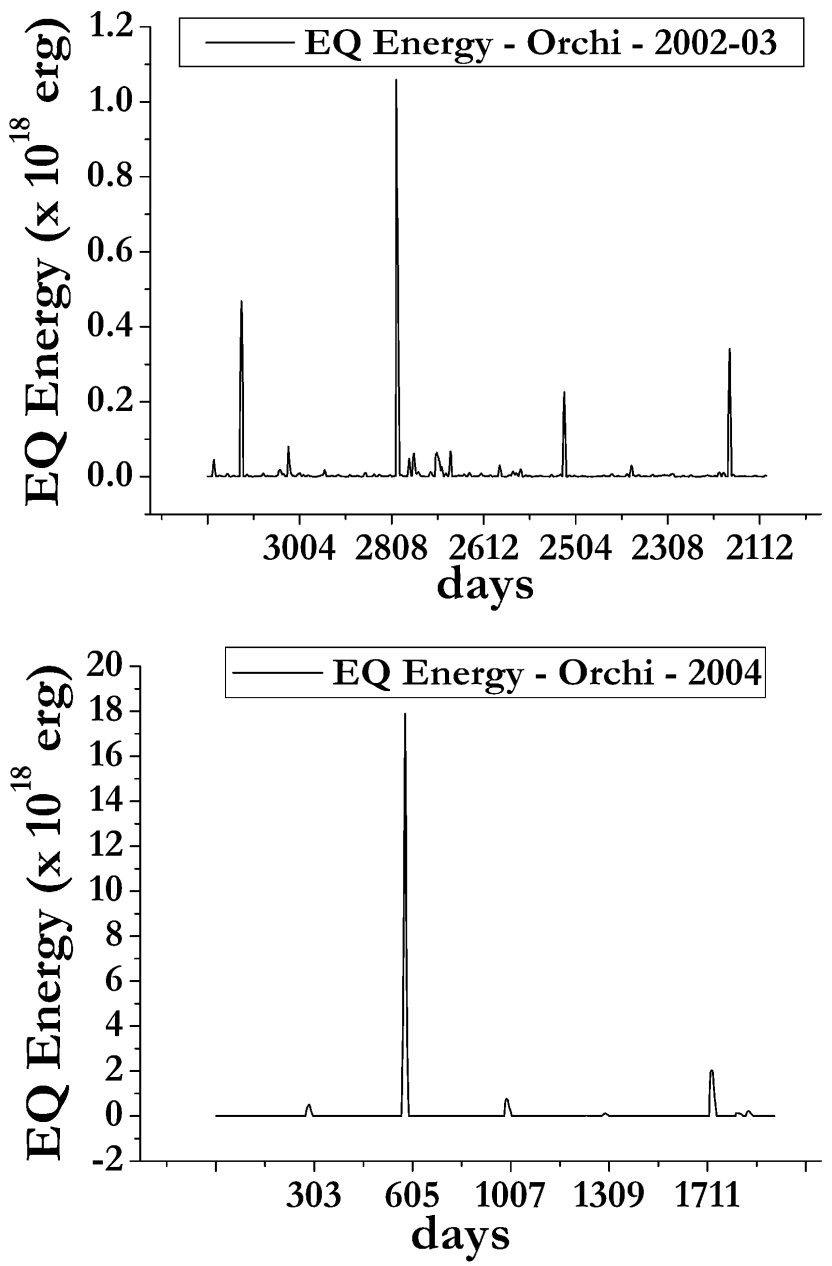

Fig. 6. Weighted time average of the total seismic energy release during a total time lag of 5 days, with epicentre within the domain $\left(41.5^{\circ} \div 44.5^{\circ}\right.$ lat., $11 .^{\circ} \div 14^{\circ} \mathrm{E}$ long.) around the Raponi site. The plot is divided into two periods, for 2002-2003 and 2004, respectively, due to the substantial difference on the ordinate axis. The distance of the epicentre from the AE recording site appears irrelevant for the phenomenon, envisaging a regional, rather than a local, control.

comparatively largely different $\Delta t$ as a function of the different mechanisms that are involved in the different case histories. The evidence is clear, both according to simple visual inspection of Fig. 1 and according to such formal analysis by means of a time delayed $\rho(\Delta t)$. But different case histories, even with epicentres in the same region, have to be considered as independent physical events, and we cannot upgrade such feature to any general rule for that given area.

As far as the LF AE are concerned, the analogous formal correlation analysis either for 2002, or for 2003, or for 2004 gives no significant evidence, denoting that the sharp change of trend, which is very clearly envisaged by direct visual inspection of Fig. 2, cannot be evidenced by such standard algorithm of $\rho(\Delta t)$. No detailed plots are here given, as their range is always within $\rho<0.2$.

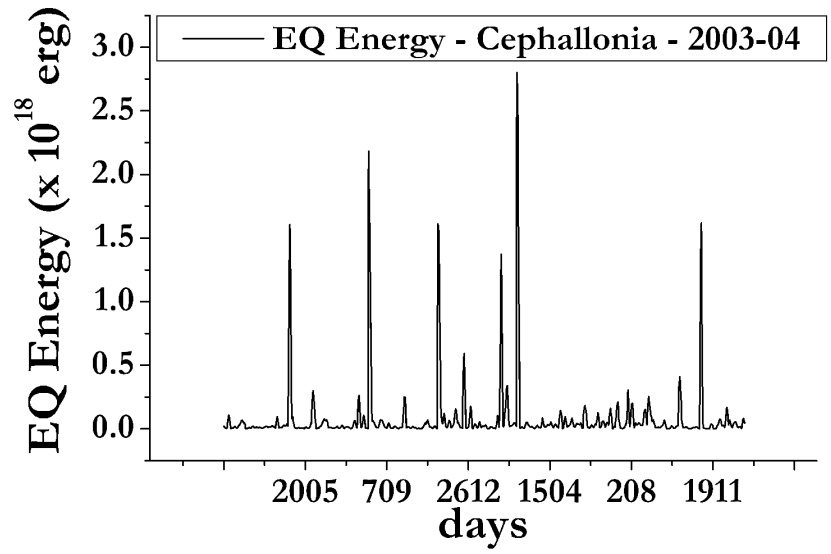

Fig. 7. Weighted time average of the total seismic energy release during a total time lag of 5 days, with epicentre within the domain $\left(37.42^{\circ} \div 39.00^{\circ}\right.$ lat., $20.12^{\circ} \div 21.12^{\circ} \mathrm{E}$ long.) around Cephallonia. Compared to the Italian peninsula, a much more frequent seismic activity is observed at Cephallonia, depending on its different tectonic setting.

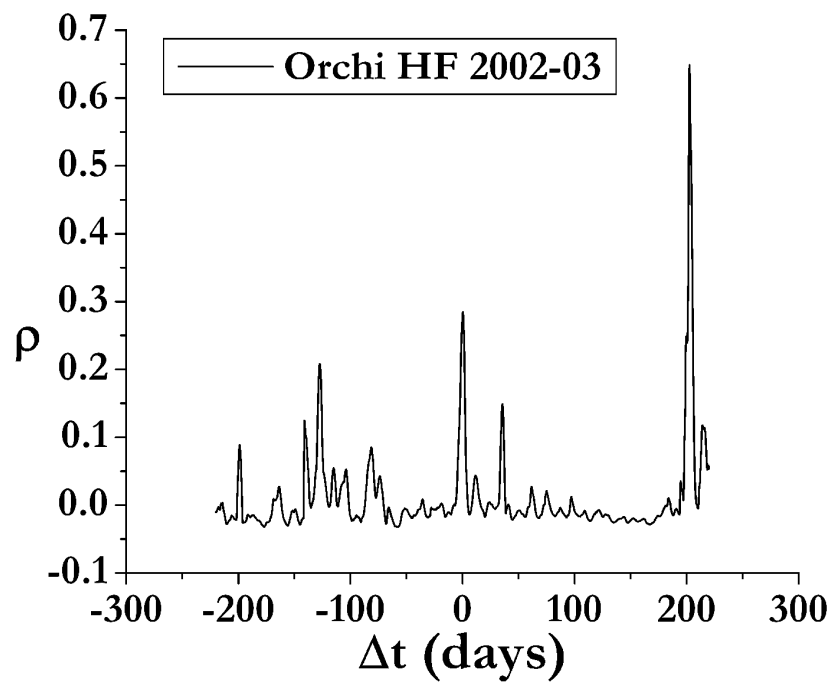

Fig. 8. Time-delayed correlation analysis between the HF AE records at the Raponi site, during 2002-2003, showing a correlation coefficient $\rho \sim 0.6$ corresponding to an HF AE precursor observed some $\sim 7$ months in advance, in agreement with the evidence inferred by direct visual inspection from Fig. 1.

Concerning Cephallonia, the HF AE data for 2003-2004 show a sharp maximum occurring $\Delta t \sim 6$ months in advance, although $\rho \sim 0.35$ is statistically insignificant (plot not here shown). The LF AE plots show a correlation with a sharp peak, with a $\rho \sim 0.42-0.52$, at $\Delta t \sim 50-60$ days before the shock for 2003 and 2004, respectively (plots not here shown). That is, as far as the time interval here investigated is concerned, they appear to be precursors, rather than aftershocks. 


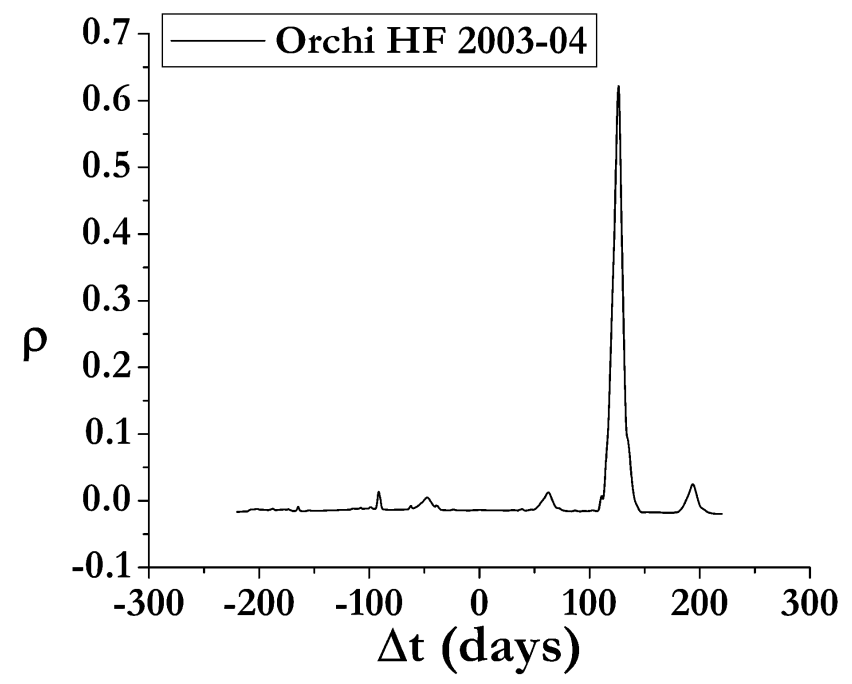

Fig. 9. The same as Fig. 8, referring to 2003-2004, showing a precursor occurring $\sim 4$ months in advance. The phenomenon is not linear, and every case history has to be considered as an independent event. See text.

\section{Discussion and conclusive remarks}

The physical system is not linear, either in the Italian peninsula, or in the comparatively different tectonic setting and environment of Cephallonia. Hence, the formal algorithms of the correlation analysis are intrinsically unsuited for giving clear evidence with any significant $\rho$. On the other hand, upon taking advantage from the great potentiality of the direct visual inspection on a plot, the $\mathrm{AE}$ records, both $\mathrm{HF}$ and LF, appear likely to display some significant precursor phenomena associated with the stress propagation through the crust, and eventually anticipating the occurrence of an earthquake.

However, every tectonic setting, like every seismic event recorded at one and the same site, displays a different behaviour, denoting a variety of different prime causes that prepare, and trigger an earthquake. Every event has to be considered as a different case history.

In addition, phenomena appear definitely non-local. That is, an earthquake depends on some accumulation of a stress field that involves processes occurring on some large area, very likely larger than the domains that were arbitrarily chosen for carrying out the analysis here reported.

Therefore, such evidences appear insufficient for deriving any final inference. Instead, in the ultimate analysis the present study shows that every significant inference should strictly require operating an array of $\mathrm{AE}$ recorders, spanning some adequately large regional area. Since every case history appears an independent event, with no direct relation with any other apparently similar event either in the same or in a different area, it makes nonsense seeking a seismic precursor by means of one observational parameter alone such as $\mathrm{AE}$, and/or by assuming any simple linear effect, which could be evidenced by means of a standard formal correlation analysis. The physical system has a large number of degrees of freedom. No single measured physical quantity alone can characterise its state. One should rather monitor, by means of $\mathrm{AE}$ or other parameters, the temporal evolution of at least some sufficiently large crustal slab, and one should then attempt at modelling the evolution of such complex system. In any case, notwithstanding no earthquake prevision in a strict sense shall ever be possible, it appears plausible that a reliable diagnosis of the evolution of the crustal stress is at our reach.

Edited by: P. F. Biagi

Reviewed by: G. Cello and another referee

\section{References}

Cello, G.: Fractal analysis of a Quaternary fault array in the central Apennines, Italy, J. Struct. Geol., 19, 945-953, 1997.

Cello, G.: A quantitative structural approach to the study of active fault zones in the Apennines (peninsular Italy), J. Geodyn., 29, 265-292, 2000.

Cello, G., Marchegiani, L., and Tondi, E.: Can we assess earthquake size by measuring the fractal dimension of active faults? Studi Geologici Camerti, Nuova Serie, 1, 73-76, 2002.

Cello, G., Gambini, R., Mazzoli, S., Read, A., Tondi, E., and Zucconi, V.: Fault zone characteristics and scaling properties of the Val d'Agri fault system (Southern Apennines, Italy), J. Geodyn., 29, 293-307, 2000.

Gregori, G. P. and Paparo, G.: Acoustic emission (AE). A diagnostic tool for environmental sciences and for non destructive tests (with a potential application to gravitational antennas), in: Meteorological and geophysical fluid dynamics (A book to commemorate the centenary of the birth of Hans Ertel), edited by: Schröder, W., Arbeitkreis Geschichte der Geophysik und Kosmische Physik, Science Edition, Bremen, 166-204, 2004.

Paparo, G., Gregori, G. P., Coppa, U., De Ritis, R., and Taloni, A.: Acoustic Emission (AE) as a diagnostic tool in geophysics, Annls Geophys., 45, 401-416, 2002.

Paparo, G. and Gregori, G. P.: Multifrequency acoustic emissions (AE) for monitoring the time evolution of microprocesses within solids, Reviews of Quantitative Nondestructive Evaluation, 22, (AIP Conference Proceedings, edited by Thompson, D. O. and Chimenti, D. E.), 1423-1430, 2003.

Paparo, G., Gregori, G. P., Poscolieri, M., Marson, I., Angelucci, F., and Glorioso, G.: Crustal stress crises and seismic activity in the Italian peninsula investigated by fractal analysis of acoustic emission (AE), soil exhalation and seismic data. Presented at the 32nd Geological International Congress, Firenze, July-August 2004, Geological Society of London, in press, 2005.

Poscolieri, M. E. L., Gregori, G. P., Paparo, G., Sakkas, V. A., Parcharidis, I., Marson, I., Soukis, K., Vassilakis, E., Angelucci, F., and Vassilopoulou, S.: Crustal stress and seismic activity in the Ionian archipelago as inferred by combined satellite and ground based observations on the Kefallinìa Island (Greece), presented at the 32nd Geological International Congress, Firenze, JulyAugust 2004, Geological Society of London, in press, 2005. 